\title{
The role of cofilin-l in vulvar squamous cell carcinoma: A marker of carcinogenesis, progression and targeted therapy
}

\author{
QIONG WU $^{1}$, YING JIANG ${ }^{1 *}$, SHOUBIN CUI $^{2^{*}}$, YANSHI WANG $^{1 *}$ and XIN WU ${ }^{1}$ \\ ${ }^{1}$ Department of Gynecology, The First Affiliated Hospital of China Medical University, Shenyang, Liaoning 110001; \\ ${ }^{2}$ Department of Gynecology and Obstetrics, Yantai Affiliated Hospital of Binzhou Medical College, \\ Yantai, Shandong 264000, P.R. China
}

Received October 30, 2015; Accepted January 5, 2016

DOI: $10.3892 / o r .2016 .4625$

\begin{abstract}
Numerous studies have revealed that cofilin-1 (CFL1) is associated with cancer cell migration and invasion in various types of tumor tissues. We investigated the roles of CFL1 in vulvar squamous cell carcinoma (VSCC). CFL1 expression was detected in VSCC and normal vulvar tissues using immunohistochemistry and western blotting. The vulvar carcinoma SW962 cell line was transfected with CFL1 small interfering RNA (siRNA) and exposed to periplocoside. We then assessed changes in cell proliferation, apoptosis, invasion and metastasis. We detected changes in CFL1 mRNA and protein expression by RT-PCR and western blotting, and alterations in protein expression of various relevant molecules by western blotting. CFL1 expression was found to be significantly upregulated in the VSCC tissues compared with the normal vulvar tissues by immunohistochemistry and western blotting $(\mathrm{P}<0.05)$ and was positively correlated with International Federation of Gynecology and Obstetrics (FIGO) stage, differentiation and lymphatic metastasis $(\mathrm{P}<0.05)$. After CFL1 knockdown by siRNA transfection, SW962 cells exhibited a decrease in growth, G1 phase cell cycle arrest, induction of apoptotic, low invasion and metastasis, and disrupted lamellipodium formation. We found that the protein expression of Bcl-xL, cyclin A1, MMP2, MMP9 and STAT3 was decreased, while expression of Bax was increased. Periplocoside inhibited SW962 cell growth, promoted apoptosis, suppressed invasion and migration, and lamellipodium formation. Periplocoside exposure resulted in lower CFL1, Bcl-xL, cyclin A1, MMP2, MMP9 and STAT3 levels, but a higher Bax level compared with the control group. We demonstrated that abnormal CFL1 expression may affect vulvar carcinogenesis and subsequent
\end{abstract}

Correspondence to: Dr Xin Wu, Department of Gynecology, The First Affiliated Hospital of China Medical University, Shenyang, Liaoning 110001, P.R. China

E-mail: xinwu.1964@aliyun.com

${ }^{*}$ Contributed equally

Key words: vulvar squamous cell carcinoma, cofilin-1, periplocoside, tumorigenesis, progression progression. CFL1 silencing by siRNA significantly inhibited VSCC cell progression, which suggests that CFL1 is a potential therapeutic target for vulvar cancer. Periplocoside, which was utilized in the present study for the clinical treatment of vulvar cancer, showed strong antitumor effects by suppression of CFL1 expression.

\section{Introduction}

Vulvar cancer (VC) is one of the most common malignancies of the female reproductive tract after cancer of the uterine corpus, ovary and cervix (1). The most common histological type is squamous cell carcinoma (SCC), which represents $\sim 95 \%$ of all VC cases (2). The incidence of vulvar squamous cell carcinoma (VSCC) has rapidly increased during the past few years $(3,4)$. Currently, radical surgery is the major treatment (5), yet postoperative recurrence and metastasis are important factors that affect the prognosis of patients with VSCC. Thus, it is important to increase our understanding of the relevant molecular mechanisms of VSCC to improve treatment and prevention.

There is growing interest related to the role of the restructuring of the actin cytoskeleton in cancer progression and metastasis. Among the many factors regulating actin cytoskeleton reorganization, cofilin-1 (CFL1) is one of the most important regulators. Wang et al observed that the protein and mRNA expression levels of CFL1 were increased in esophageal squamous cell carcinoma (ESCC), and CFL1 overexpression promoted the development of ESCC (6). In addition, a previous study found that the cofilin pathway was closely associated with the ability of breast cancer cells to invade and metastasize $(7,8)$. However, CFL1 expression and its role in VSCC is unclear; therefore, in the present study we aimed to explore the influence of CFL1 on VSCC.

\section{Materials and methods}

Patient specimens. We investigated formalin-fixed and paraffin-embedded VSCC tissues from 35 patients with VSCC (without preoperative radiotherapy and chemotherapy) and formalin-fixed and paraffin-embedded normal vulvar tissues from 20 patients that underwent plastic surgery of the vulva. The archived tissues were retrieved from the Department 
of Gynecological Pathology at China Medical University, Shenyang, China, from June 2003 to June 2013. We previously ensured that the tissues were diagnosed by two experienced pathologists and de-identified prior to use. The average age of the VSCC patients was 55.9 \pm 3.6 years (range, 32-75 years). According to the International Federation of Gynecology and Obstetrics (FIGO) staging, 8 of the 35 patients presented with VSCC stage I, 17 with stage II, and 10 with stage III; 19 cases exhibited high differentiation, 10 cases had moderate differentiation, and 6 cases had poor differentiation. Ten cases suffered from lymph node metastasis and 25 cases were without lymph node metastasis.

Immunohistochemistry. Xylene was used to deparaffinize consecutive sections of the paraffin-embedded tissues, and different concentrations of alcohol were used to rehydrate these sections. For antigen retrieval, the sections were placed into $0.01 \mathrm{M}$ citrate buffer, then into a pressure cooker and heated to boiling for $2 \mathrm{~min}$. The sections were immersed in $3 \%$ $\mathrm{H}_{2} \mathrm{O}_{2}$ at $37^{\circ} \mathrm{C}$ for $20 \mathrm{~min}$ to inactivate endogenous peroxidase. Non-specific binding was prevented by adding $2 \%$ goat serum albumin for $30 \mathrm{~min}$. The sections were immersed in the CFL1 antibody (Proteintech Group, Chicago, IL, USA) overnight at $4^{\circ} \mathrm{C}$; and incubated with anti-mouse $\operatorname{IgG}(1: 5,000)$ at $37^{\circ} \mathrm{C}$ for $15 \mathrm{~min}$ and horseradish peroxidase-labeled streptavidin solution (S-A/HRP) (both from Beijing Zhongshan Golden Bridge Biotechnology Co., Ltd., Beijing, China) for another $15 \mathrm{~min}$ the following day. After staining with $0.05 \%$ diaminobenzidine (DAB; Beijing Zhongshan Golden Bridge Biotechnology Co., Ltd.), the sections were counterstained using hematoxylin, then dehydrated, cleared and mounted. For the negative control (NC), phosphate-buffered saline (PBS) was utilized instead of the primary antibody. Finally, we used the Metamorph system to measure the optical density (OD) value.

Western blot analysis. The protein concentrations of $10 \mathrm{VSCC}$ and 10 normal vulvar tissues were determined via a protein assay kit (Beyotime Biotechnology, Co., Ltd., Shanghai, China) according to the manufacturer's protocol. Total denatured proteins were isolated by $10 \%$ sodium dodecyl sulfate-polyacrylamide gel electrophoresis (SDS-PAGE), then transferred to Hybond membranes (Amersham, Munich, Germany) for at least $2 \mathrm{~h}$, and blocked overnight in 5\% fatfree milk. The membranes were immersed in the primary antibody against CFL1 for at least $2 \mathrm{~h}$. Next, the membranes were rinsed three times with TBST and incubated with the secondary antibody (anti-mouse IgG antibodies; 1:5,000; Beijing Zhongshan Golden Bridge Biotechnology Co., Ltd.) for $2 \mathrm{~h}$. Finally, we analyzed specific bands using ImageQuant LAS 4000 (Fujifilm, Tokyo, Japan) and ECL Plus detection reagents (Beyotime Biotechnology, Co., Ltd.).

Cell culture and CFL1 knockdown and inhibition. Vulvar carcinoma cell line SW962 was purchased from Guangzhou Jennio Biotech Co., Ltd. (Guangzhou, China) and was grown in RPMI-1640 medium containing $10 \%$ fetal bovine serum (FBS), $100 \mathrm{U} / \mathrm{ml}$ penicillin and $100 \mu \mathrm{g} / \mathrm{ml}$ streptomycin under a humidified atmosphere of $5 \% \mathrm{CO}_{2}$ at $37^{\circ} \mathrm{C}$. The medium was replaced every two days, and the cells were subcultured at $\sim 80 \%$ confluency. For CFL1 knockdown, we used CFL1 small interfering RNA (siRNA) transfectants (Sigma-Aldrich, St. Louis, MO, USA). The target CFL1 sequences were: 5'-GA AGGAGGAUCUGGUGUUUdTdT-3' (sense) and 5'-AAA CACCAGAUCCUCCUUCdTdT-3' (antisense); the NC siRNA sequences were: 5'-UUCUCCGAACGUGUCACGUTT-3' (sense) and 5'-ACGUGACACGUUCGGAGAATT-3' (antisense) (Sigma-Aldrich). Periplocoside (Shanghai Nature Standard R\&D and Biotech Co., Ltd., Shanghai, China), a CFL1 inhibitor, was dissolved in dimethyl sulfoxide (DMSO) to different concentrations as described below when required for the assays.

Cell proliferation assay. We used the MTT assay to explore the effect of CFL1 siRNA transfectants and periplocoside on SW962 cell growth. Briefly, $5 \times 10^{3}$ cells/well were plated into 96-well plates and treated with CFL1 siRNA and periplocoside at concentrations of $0,0.125,0.25,0.5,1.0,2.0$ and $4.0 \mu \mathrm{M}$. At time points $0,24,48$ and $72 \mathrm{~h}$, MTT was added into each well, and the cells were incubated for $4 \mathrm{~h}$; then DMSO (both from Beijing Solarbio Science and Technology Co., Ltd., Beijing, China) was added to each well and measured at a wavelength of $490 \mathrm{~nm}$.

Flow cytometric apoptosis assay. Flow cytometry was carried out with cells stained with propidium iodide (PI) and FITClabeled Annexin V (BD Biosciences, San Jose, CA, USA) in accordance with the manufacturer's instructions. Briefly, following the incubation of the cells treated with CFL1 siRNA and $0,0.125,0.25$ and $0.5 \mu \mathrm{M}$ of periplocoside for $48 \mathrm{~h}$, the cells were rinsed twice with PBS, and then resuspended in $100 \mu 1$ $1 \mathrm{X}$ binding buffer at a density of $1 \times 10^{5}$ cells $/ \mathrm{ml}$. Next, $5 \mu \mathrm{l}$ of FITC Annexin V and $5 \mu 1$ PI were added to each sample. The samples were gently vortexed and incubated for $15 \mathrm{~min}$ at $25^{\circ} \mathrm{C}$ in the dark. Finally, $400 \mu \mathrm{l}$ of $1 \mathrm{X}$ binding buffer was added, and the cells were analyzed by flow cytometry within $1 \mathrm{~h}$.

Cell cycle analysis. After treatment of the cells with CFL1 siRNA and $0,0.125,0.25$ and $0.5 \mu \mathrm{M}$ of periplocoside for $48 \mathrm{~h}$ at $37^{\circ} \mathrm{C}$ in an atmosphere of $5 \% \mathrm{CO}_{2}$, the cells were digested using $0.25 \%$ trypsin, harvested and washed twice with PBS at a density of $1 \times 10^{6}$ cells $/ \mathrm{ml}$. A total of $500 \mu 1$ of ice-cold ethanol was added to each tube equipped with $1 \mathrm{ml}$ of cell suspension for at least $2 \mathrm{~h}$ and stored at $4^{\circ} \mathrm{C}$. Next, the cells were washed twice with PBS, and PI containing RNase A (BD Biosciences) was added, and the cells were cultivated at $4^{\circ} \mathrm{C}$ in the dark for $30 \mathrm{~min}$. The cells were examined using flow cytometry at a wavelength of $488 \mathrm{~nm}$.

Wound healing assay. To investigate cell migration ability, we used a wound-healing assay. The cells were plated at $1.0 \times 10^{6}$ cells $/$ well in 6 -well plates. At $~ 90 \%$ confluency, the cells were wounded with a sterile $200-\mu 1$ pipette tip, washed twice with PBS, and grown in FBS-free medium. CFL1 siRNAs and different concentrations of periplocoside were added to each well. Images of cells were captured at 0,24 and $48 \mathrm{~h}$.

Cell invasion assay. To investigate cell invasiveness, we used a cell invasion assay. A thin layer of Matrigel (Becton-Dickinson Labware, Bedford, MA, USA) was spread on top of $6.5-\mathrm{mm}$ Transwell chambers (BD Biosciences). We placed the plates 
Table I. Primers for RT-PCR.

\begin{tabular}{|c|c|c|c|c|c|}
\hline Gene & & Primer sequence & $\begin{array}{c}\text { Annealing } \\
\text { temperature }\left({ }^{\circ} \mathrm{C}\right)\end{array}$ & $\begin{array}{l}\text { Product } \\
\text { size (bp) }\end{array}$ & $\begin{array}{c}\text { Extension time } \\
(\mathrm{sec})\end{array}$ \\
\hline \multirow[t]{2}{*}{ Cofilin-1 } & $\mathrm{F}$ & 5'-GCCGCTATGCCCTCTA-3' & & & \\
\hline & $\mathrm{R}$ & 5'-CAATTCATGCTTGATCCCT-3' & 60 & 167 & 34 \\
\hline \multirow[t]{2}{*}{$18 \mathrm{~s}$} & $\mathrm{~F}$ & 5'-ACGGACAGGATTGACAGATT-3' & & & \\
\hline & $\mathrm{R}$ & 5'-GGCGTAGGGTAGGCACA-3' & 60 & 288 & 34 \\
\hline
\end{tabular}

Table II. Correlation between cofilin-1 expression and the clinicopathological features of the VSCC cases.

\begin{tabular}{lccc}
\hline Clinical features & $\begin{array}{c}\text { Cases } \\
(\mathrm{n})\end{array}$ & $\begin{array}{c}\text { Mean optical } \\
\text { density }\end{array}$ & P-value \\
\hline Age (years) & & & \\
$\quad<45$ & 8 & $0.3363 \pm 0.0086$ & 0.195 \\
$\geq 45$ & 27 & $0.3426 \pm 0.0132$ & \\
LN metastasis & & & \\
Positive & 10 & $0.3490 \pm 0.0047$ & 0.005 \\
$\quad$ Negative & 25 & $0.3369 \pm 0.0127$ & \\
FIGO stage & & & \\
III & 10 & $0.3420 \pm 0.0127$ & 0.001 \\
I-II & 25 & $0.3287 \pm 0.0051$ & \\
Differentiation & & & 0.001 \\
High & 19 & $0.3383 \pm 0.0123$ & \\
Moderate/poor & 16 & $0.3489 \pm 0.0065$ & \\
\hline
\end{tabular}

VSCC, vulvar squamous cell carcinoma; LN, lymph node.

in a $37^{\circ} \mathrm{C}$ incubator for $4 \mathrm{~h}$ to solidify the Matrigel. Culture medium was then added to the bottom of the Transwell chambers. The cells resuspended in serum-free RPMI-1640 were added to the top of the Transwell chambers. Cells were treated with CFL1 siRNAs or $0,0.125,0.25$ and $0.5 \mu \mathrm{M}$ of periplocoside. After incubation for $48 \mathrm{~h}$, the cells that remained on the top of the chambers were removed by cotton swabs, and the cells that had invaded the Matrigel and reached the bottom of the filters were fixed in methyl alcohol. The cells were then stained with $0.1 \%$ crystal violet. The number of invaded cells was counted using a Olympus fluorescence microscope (Tokyo, Japan).

Immunofluorescence. After placing coverslips in 6-well plates, we seeded the cells at 100 cells/well. Subsequently, we discarded the medium and exposed the cells to CFL1 siRNAs and different concentrations of periplocoside for $48 \mathrm{~h}$. We washed the cells twice with PBS, and fixed the cells with $4 \%$ formaldehyde for $10 \mathrm{~min}$. Then the cells were permeabilized with $0.2 \%$ Triton $\mathrm{X}-100$ for $10 \mathrm{~min}$ at $25^{\circ} \mathrm{C}$. Next, the cells were incubated overnight at $4^{\circ} \mathrm{C}$ with Alexa Fluor ${ }^{\circledR} 594$ phalloidin (Invitrogen Carlsbad, CA, USA) to visualize the lamellipodia after being washed twice with PBS. The following day, we added $1 \mu \mathrm{g} / \mathrm{ml}$ 4',6-diamidino-2-phenylindole (DAPI) (Sigma-
Aldrich) and incubated the cells at $37^{\circ} \mathrm{C}$ for $15 \mathrm{~min}$ to stain the cell nuclei. Finally, the coverslips were observed under a confocal laser microscope (Leica, Solms, Germany).

Real-time reverse transcription-polymerase chain reaction $(R T-P C R)$. According to the manufacturer's protocol, we used TRIzol (Takara, Dalian, China) to extract RNA from the SW962 cells transfected with CFL1 siRNAs and exposed to 0 , $0.125,0.25$ and $0.5 \mu \mathrm{M}$ of periplocoside for $48 \mathrm{~h}$. Subsequently, we used a Reverse Transcription System kit A5001 (Promega, Madison, WI, USA) to reverse transcribe total RNA to complementary DNA (cDNA). The PCR primers were from GenBank sequences (Table I). Augmentation of the cDNA was carried out in 20- $\mu 1$ mixtures according to GoTaq qPCR Master Mix A6001 (Promega), and the internal control was glyceraldehyde-3-phosphate dehydrogenase (GAPDH).

Western blot analysis. The protein concentration of cells transfected with CFL1 siRNAs and periplocoside $(0,0.125$, 0.25 and $0.5 \mu \mathrm{M}$ ) for $48 \mathrm{~h}$ was determined by a protein assay kit (Bio-Rad Laboratories, Hercules, CA, USA) according to the manufacturer's protocol. Total denatured proteins were separated by $10 \%$ SDS-PAGE and transferred to Hybond membranes for at least $2 \mathrm{~h}$, and then blocked overnight in $5 \%$ fat-free milk. The membranes were incubated for at least $2 \mathrm{~h}$ with antibodies against CFL1, cyclin A1, MMP2 and MMP9 (Proteintech Group), Bax, Bcl-xL and STAT3 (Boster Biological Technology, Ltd., Wuhan, China) for immunoblotting. Next, we washed all of the membranes three times with TBST and incubated them with secondary antibodies (anti-mouse or anti-rabbit IgG antibodies; 1:5,000; Dako, Carpinteria, CA, USA) for $2 \mathrm{~h}$. Bands were observed using ImageQuant LAS 4000 (Fujifilm) and ECL Plus detection reagents (Beyotime Biotechnology, Co., Ltd.).

Statistical analysis. All experiments were repeated three or more times. The evaluation of statistics was performed using the t-test to analyze the measurement data and the MannWhitney $\mathrm{U}$ test to compare the means of the different groups. A P-value of $<0.05$ was considered to indicate a statistically significant result. SPSS 17.0 (SPSS, Inc., Chicago, IL, USA) was used to analyze all data.

\section{Results}

Expression of CLF1 protein in the VSCC tissues and the relationship of CFL1 expression to clinicopathological features of VSCC. Immunohistochemistry indicated that CFL1 
A

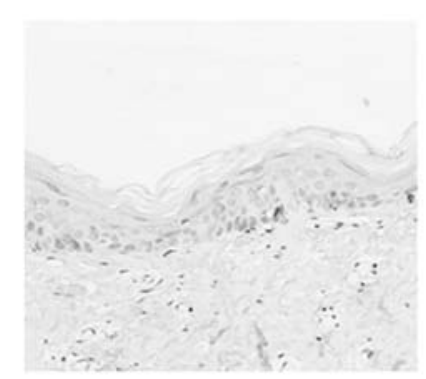

C

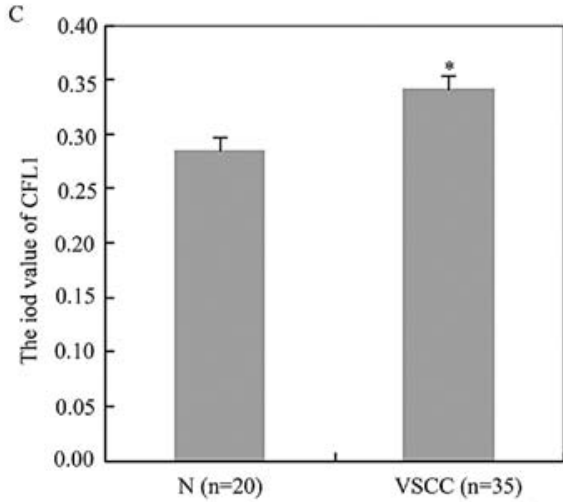

$\mathrm{E}$

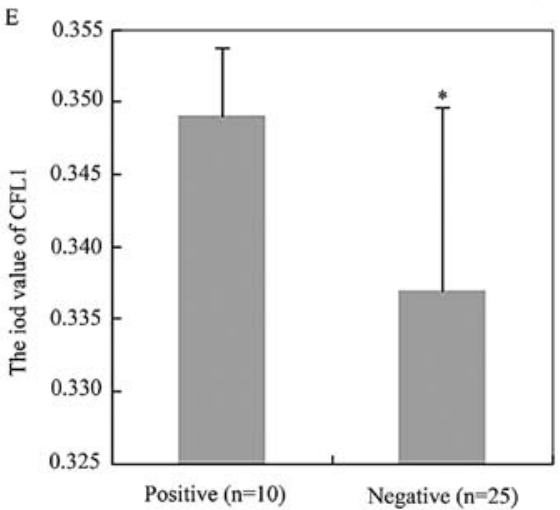

B

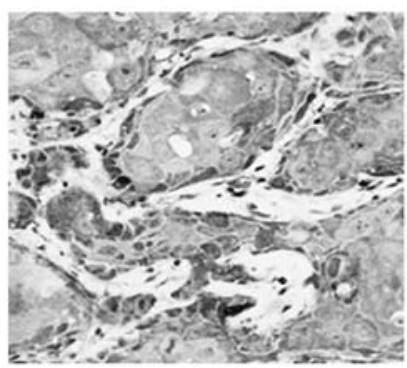

D
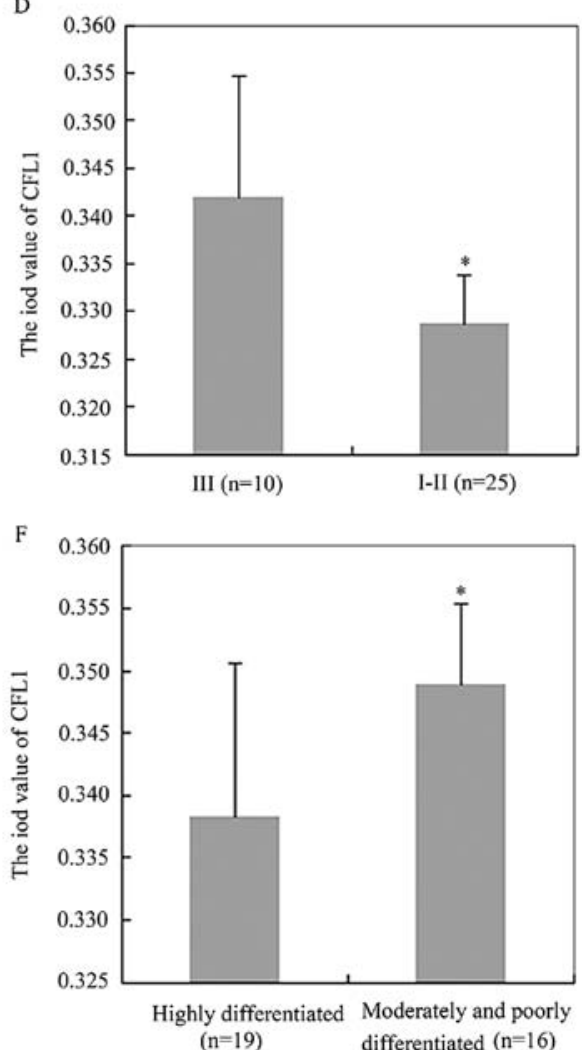

Figure 1. CFL1 protein expression in VSCC tissues as determined by immunohistochemistry. (A-C) The CFL1 expression level was higher in the VSCC tissues than that in the normal vulvar skin tissues. (D-F) CFL1 expression was significantly higher in stage III VSCC tissues than that in stage I-II VSCC tissues (D), in cases with lymph node metastasis than that in cases without lymph node metastasis (E), in moderately and poorly differentiated tissues than that in highly differentiated VSCC tissues (F). Data are expressed as the mean \pm standard deviation, ${ }^{*} \mathrm{P}<0.05$.
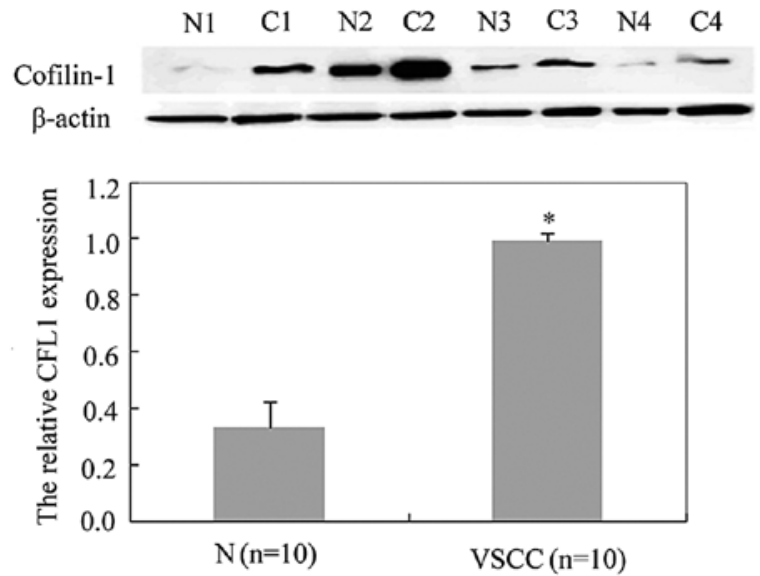

Figure 2. CFL1 protein expression in VSCC as determine by western blotting. The expression of CFL1 in normal vulvar cells was decreased compared with the expression in VSCC cells. Data are expressed as the mean \pm standard deviation, ${ }^{*} \mathrm{P}<0.05$. expression was higher in the VSCC tissues (average OD value, $0.3410 \pm 0.0120$ ) than that in the normal vulvar tissues (average OD value, 0.2849 \pm 0.0116 ) (Fig. 1A-C; $\mathrm{P}<0.05$ ). Subsequently, we found that CFL1 expression was positively associated with FIGO stage (Fig. 1D; P<0.05), lymphatic metastasis (Fig. 1E; $\mathrm{P}<0.05$ ) and dedifferentiation (Fig. 1F; $\mathrm{P}<0.05$ ) by immunohistochemistry, while CFL1 expression was not correlated with the age of the VSCC patients ( $\mathrm{P}>0.05$; Table II). In addition, western blot analysis confirmed a similar result; the expression of CFL1 in normal vulvar cells (relative CFL1 expression, $0.33 \pm 0.09)$ was decreased compared with the expression in

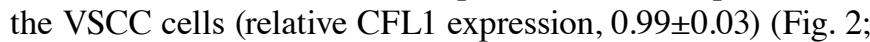
$\mathrm{P}<0.05)$.

Effects of CFL1 knockdown on the phenotype and expression of related molecules in the VSCC cells. In Fig. 3A, we showed that levels of CFL1 mRNA and protein expression were highest in the SW962 cells, and CFL1 expression in the SW962 cells 
A

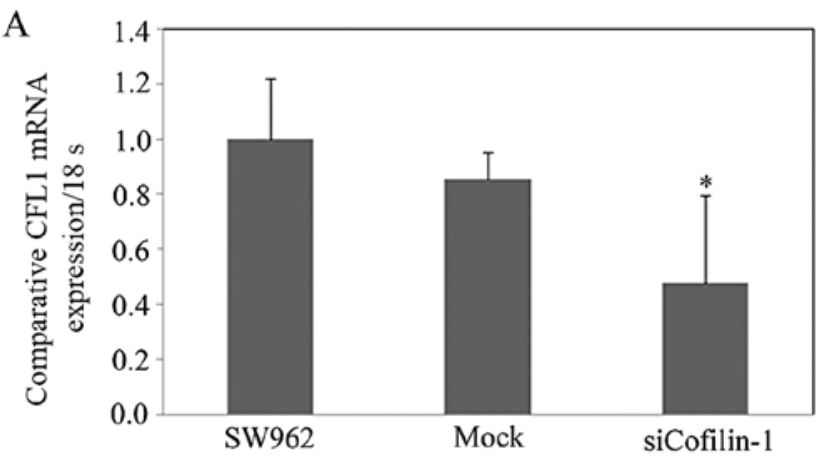

CFL1
B

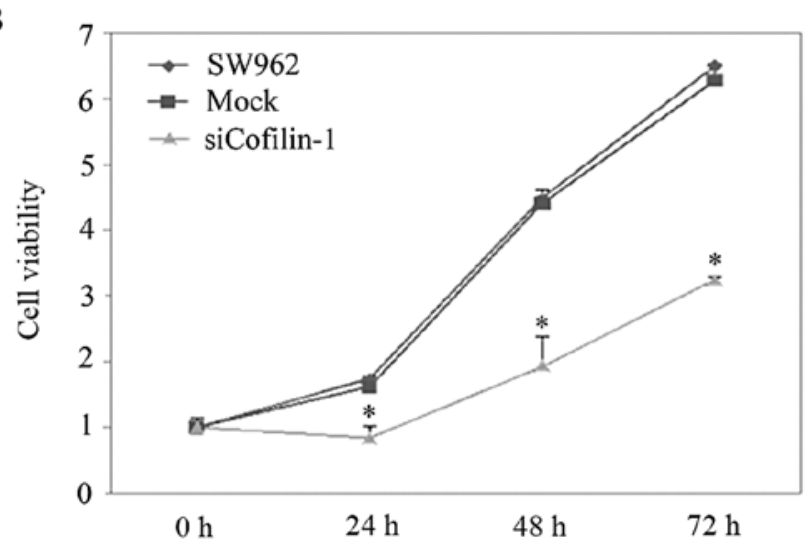

Figure 3. Effects of CFL1 knockdown on vulvar carcinoma cell proliferation. Following siCofilin-1 transfection, SW962 cells exhibited significantly lower CFL1 expression (A) and slower growth (B) compared with the control and mock cells. Data are expressed as the mean \pm standard deviation, ${ }^{*} \mathrm{P}<0.05$.
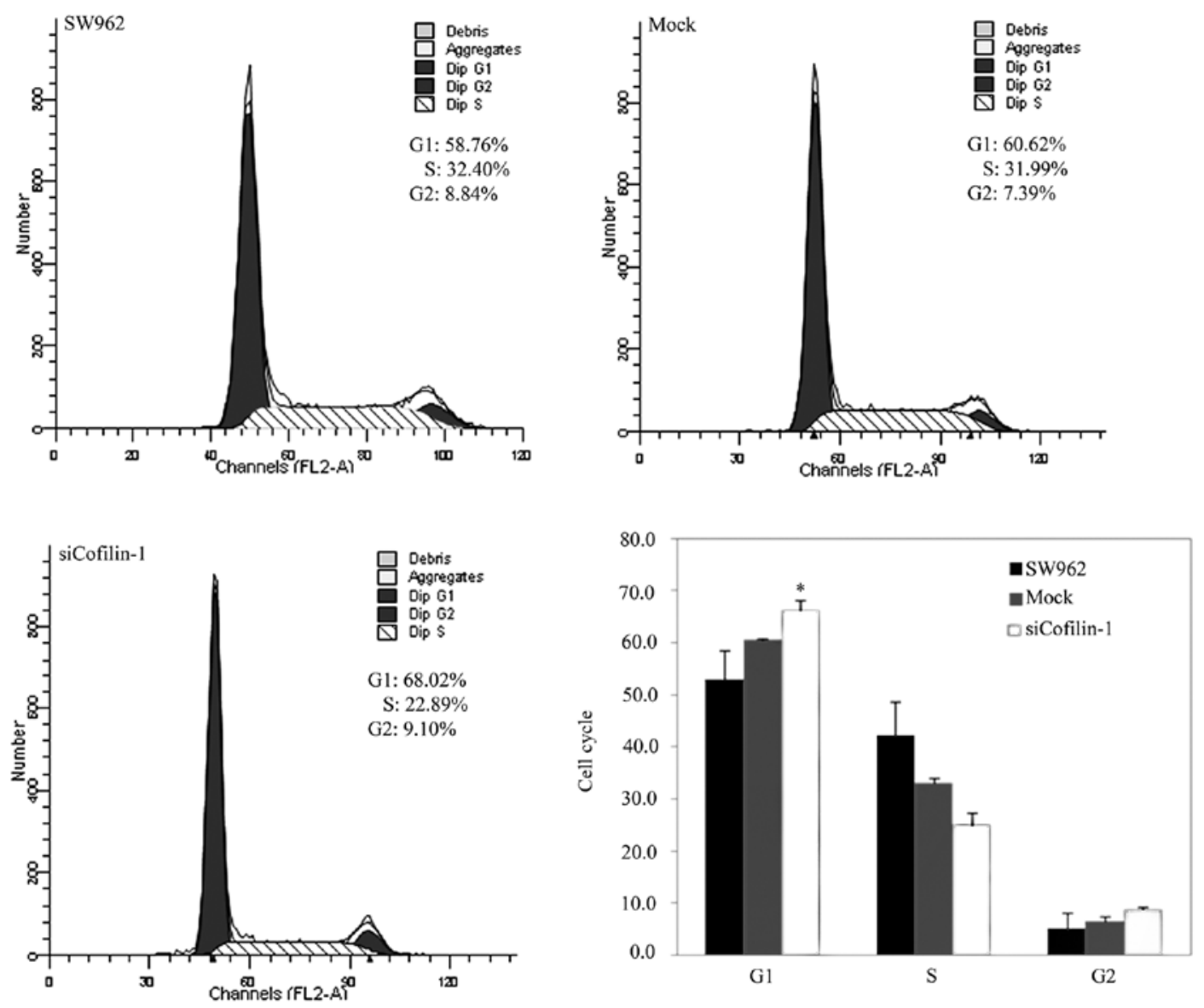

Figure 4. Effects of CFL1 knockdown on the cell cycle distribution of the vulvar carcinoma cells. Following siCofilin-1 transfection, the SW962 cells exhibited induced G1 arrest compared with the control and mock cells. Data are expressed as the mean \pm standard deviation, ${ }^{*} \mathrm{P}<0.05$.

treated with CFL1 siRNA transfectants was weaker when compared with levels in the NC or mock-treated cells according to real-time PCR and western blot assays $(\mathrm{P}<0.05)$. According to the MTT assay, we found that cells transfected with CFL1 siRNA grew significantly slower than the rate in the $\mathrm{NC}$ and mock-transfected cells (Fig. 3B; P $<0.05$ ). Cell transfected with CFL1 siRNA exhibited G1 phase arrest according to PI staining and flow cytometry (Fig. 4; $\mathrm{P}<0.05$ ), and showed a significantly higher apoptosis rate by Annexin V-fluorescein isothiocyanate (FITC) staining (Fig. 5; $\mathrm{P}<0.05$ ). Based on the scratch test and the Transwell invasion assay, CFL1 silencing suppressed cell motility (Fig. 6; $\mathrm{P}<0.05$ ) and invasion (Fig. 7; $\mathrm{P}<0.05)$ compared with the motility and invasion of the $\mathrm{NC}$ and mock-transfected cells. In addition, cells with silenced 

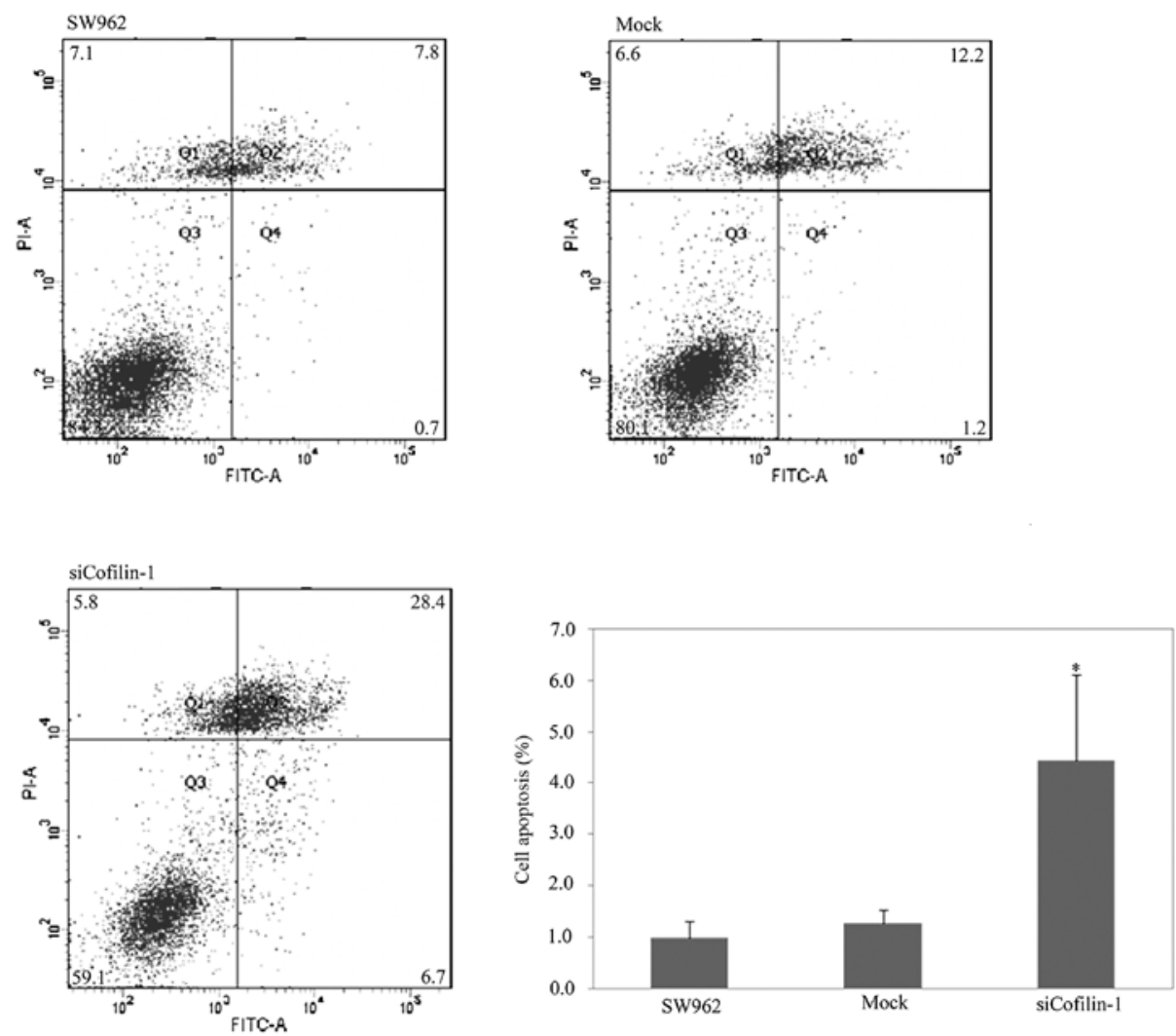

Figure 5. Effects of CFL1 knockdown on vulvar carcinoma cell apoptosis. Following siCofilin-1 transfection, the SW962 cells exhibited induced G1 apoptosis compared with the control and mock cells. Data are expressed as the mean \pm standard deviation, ${ }^{*} \mathrm{P}<0.05$.
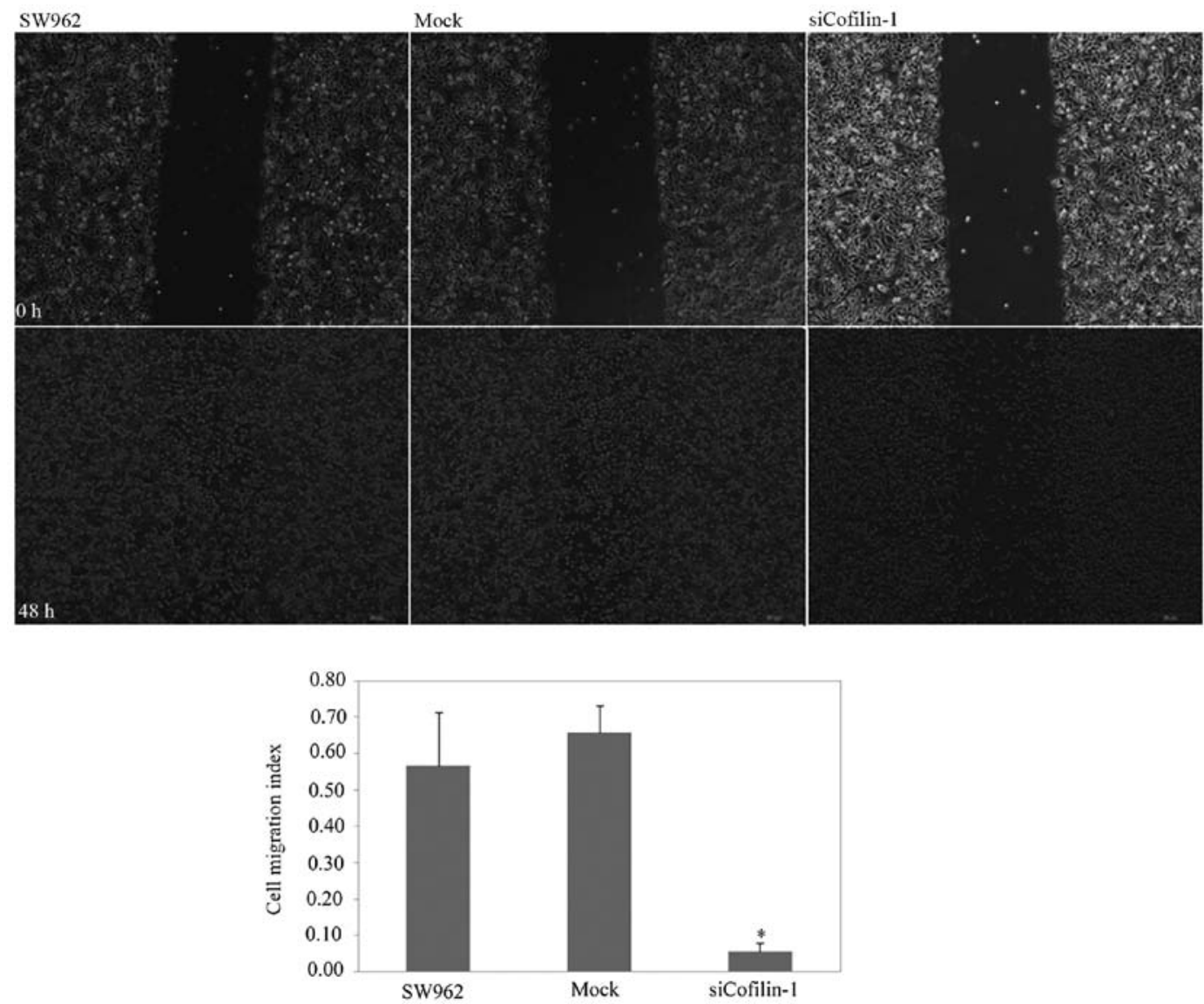

Figure 6. Effects of CFL1 knockdown on vulvar carcinoma cell migration. Following siCofilin-1 transfection, the SW962 cells exhibited significantly reduced migration ability compared with the control and mock cells. Data are expressed as the mean \pm standard deviation, ${ }^{*} \mathrm{P}<0.05$. 

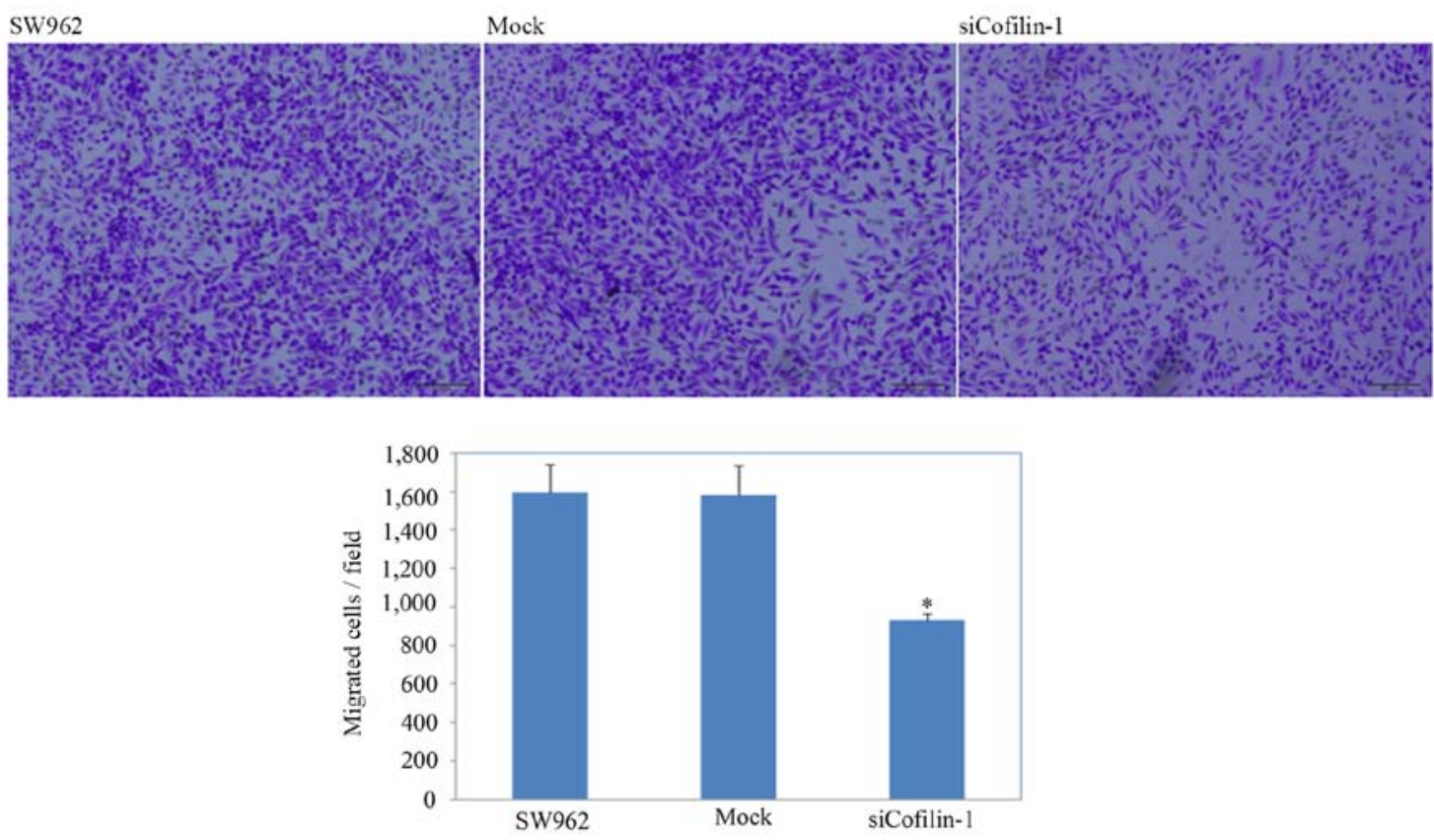

Figure 7. Effects of CFL1 knockdown on vulvar carcinoma cell invasion. Following siCofilin-1 transfection, the SW962 cells exhibited significantly reduced invasion ability compared with the control and mock cells. Data are expressed as the mean \pm standard deviation, ${ }^{*} \mathrm{P}<0.05$.

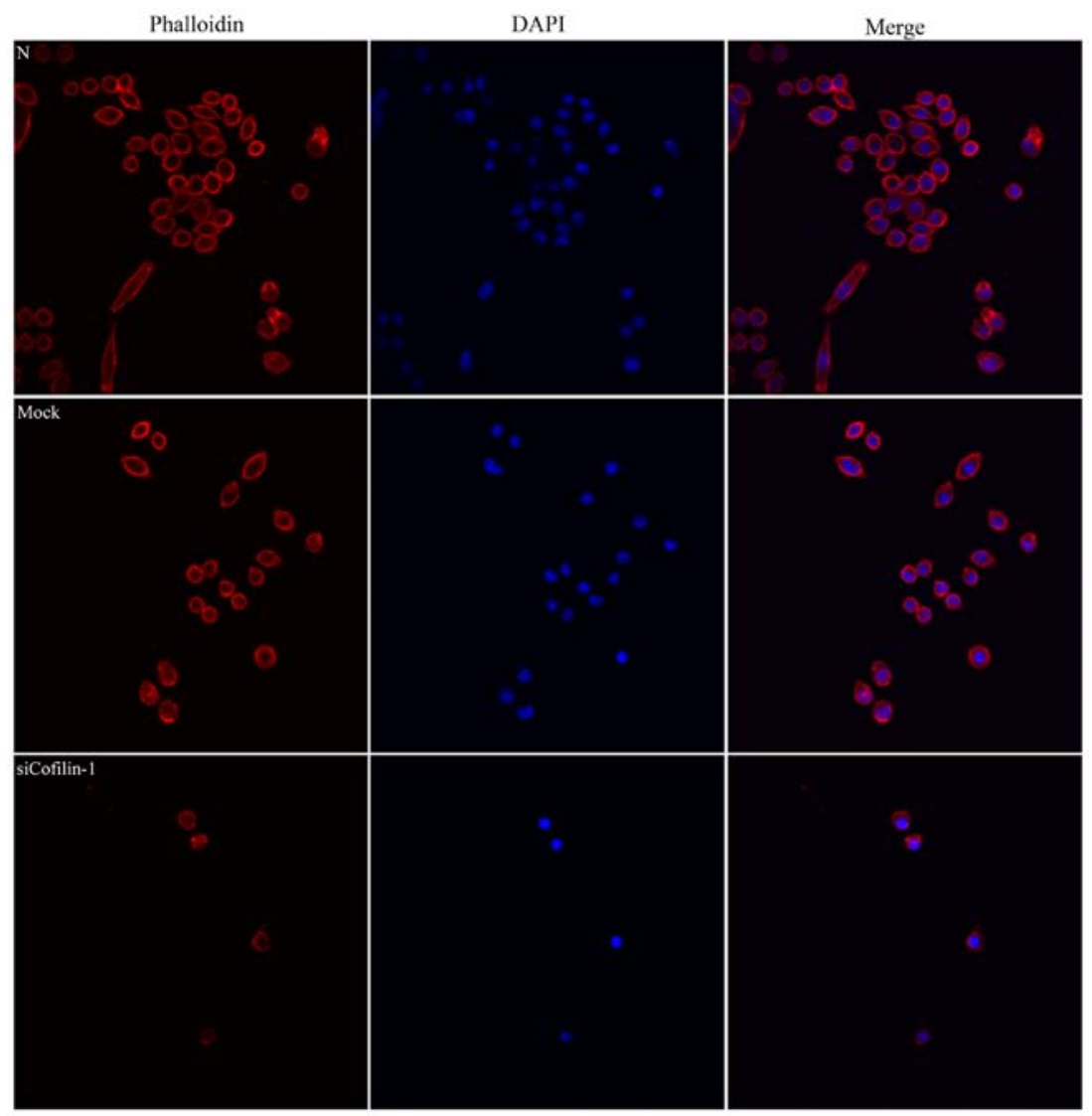

Figure 8. CFL1 knockdown suppresses vulvar carcinoma cell lamellipodium formation. SiCofilin-1 transfection suppressed SW962 cell lamellipodium formation compared with the control and mock cells.

CFL1 had inhibited lamellipodium formation as indicated by the F-actin structure (Fig. 8). In cells transfected with the CFL1 siRNA transfectants, we found that the protein expres- sion levels of MMP2, MMP9, cyclin A1, STAT3 and Bcl-xL were downregulated, while the Bax level was upregulated by western blot assay (Fig. 9). 


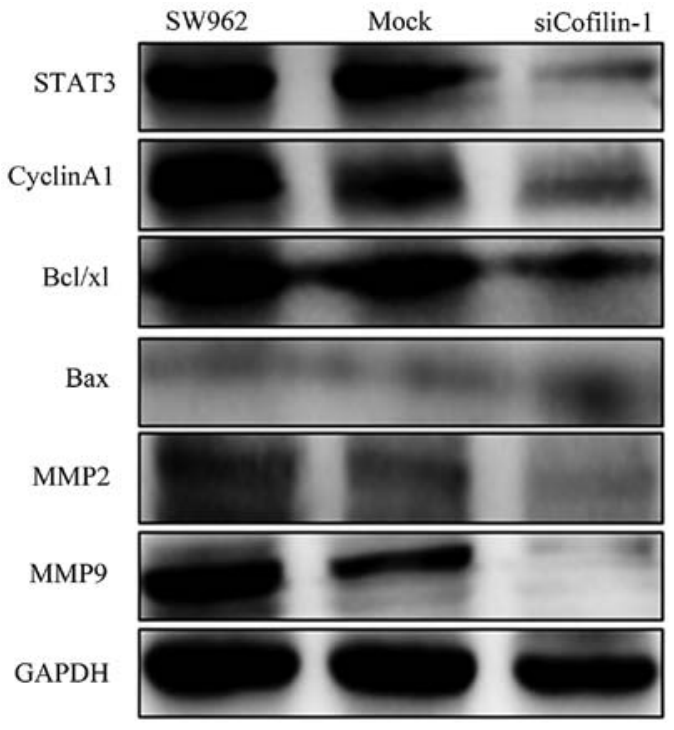

Figure 9. Effects of CFL1 knockdown on vulvar carcinoma cell genotype. Cofilin-1 siRNA transfection downregulated MMP2, MMP9, cyclin A1, STAT3, and Bcl-xL protein expression while upregulated Bax protein expression in the SW962 cells.

Effects of periplocoside on the phenotype and expression of related molecules in the VSCC cells. We found that periplocoside decreased CFL1 expression in the SW962 cells. Additionally, SW962 cells treated with periplocoside exhibited less proliferative capability compared with that of the NC in a dose-dependent manner as determined the MTT assay (Fig. 10; $\mathrm{P}<0.05$ ). Periplocoside exposure induced G1 phase arrest (Fig. 11; $\mathrm{P}<0.05$ ) by cell cycle assay, and resulted in the promotion of apoptosis in comparison with NC (Fig. 12; $\mathrm{P}<0.05$ ), as shown by flow cytometric apoptosis analysis. Wound-healing and invasion assays showed that periplocoside was able to reduce cell migration (Fig. 13; $\mathrm{P}<0.05$ ) and invasion (Fig. 14; $\mathrm{P}<0.05$ ) abilities of the SW962 cells, and immunofluorescence revealed that periplocoside destroyed lamellipodium formation (Fig. 15). After treatment with periplocoside, we utilized western blot analysis to assess the levels of MMP2, MMP9, Bax, cyclin A1, STAT3 and Bcl-xL protein expression in the SW962 cells and found that all proteins were downregulated except for the level of Bax which was increased (Fig. 16).

\section{Discussion}

CFL1 is the ubiquity of small proteins, $\sim 19 \mathrm{kDa}$, contributing to cytoskeletal dynamics through accelerating the abscission and depolymerization of actin filaments. CFL1 plays an important role in cytokinesis, cell motility and morphogenesis (9). A number of studies have reported that CFL1 is associated with cancer cell migration and invasion capability, which are significant features of malignant tumor cells in various solid tumor tissues $(7,9,10)$. Lu et al reported that CFL1 was upregulated and significantly associated with the presence of lymph node metastasis, based on immunohistochemistry (11). In addition, a previous study reported that the expression of CFL1 in ovarian carcinoma tissues was significantly higher than that in borderline ovarian tumor and benign ovarian
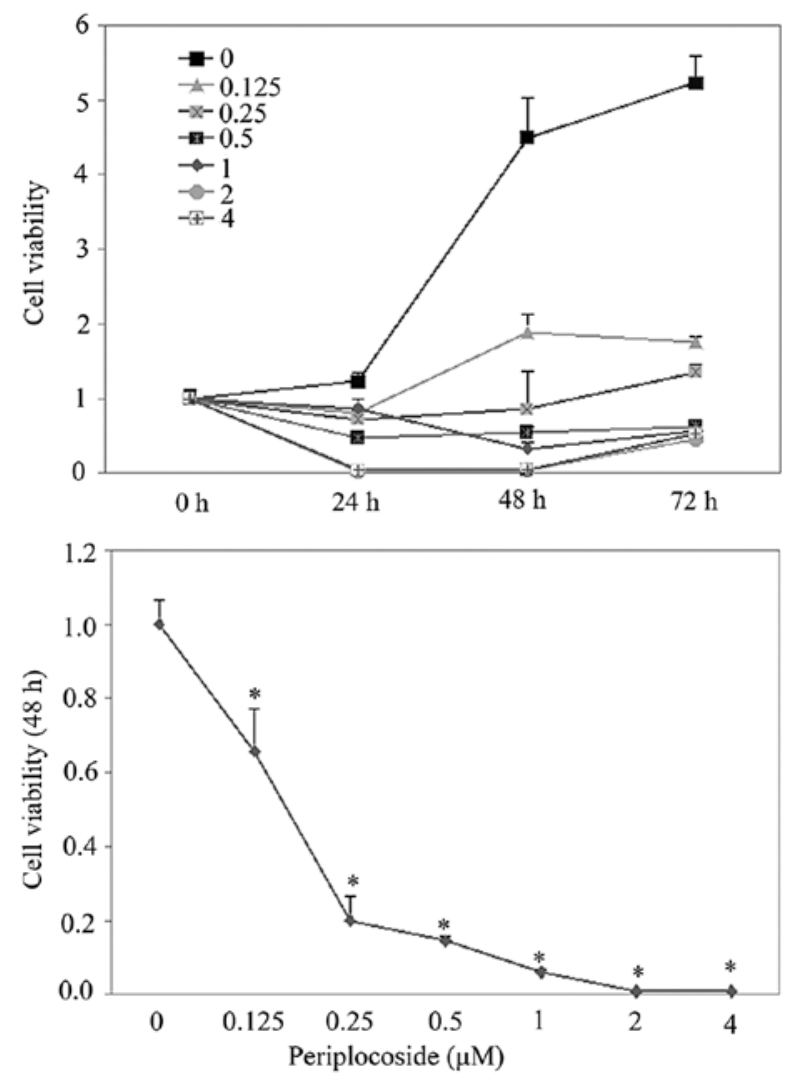

Figure 10. Effects of periplocoside on vulvar carcinoma cells. SW962 cells treated with periplocoside exhibited less proliferative capability compared with that in the NC in a dose-dependent manner. Data are expressed as the mean \pm standard deviation, ${ }^{*} \mathrm{P}<0.05$.

tissues by immunohistochemistry, and that the expression of CFL1 was positively associated with the degree of ovarian cancer differentiation (12). In the present study, we found that CFL1 expression was significantly upregulated in VSCC cells compared with that in normal vulvar tissues by immunohistochemistry and western blotting, and was positively correlated with clinical stage (according to the FIGO staging system), degree of differentiation and lymphatic metastasis, which was consistent with previous findings. Taken together, CFL1 expression is associated with VSCC aggressiveness and tumor progression.

To determine the concrete biological function of the CFL1 protein in VSCC, SW962 cells were subjected to CFL1 knockdown using siRNA transfection. We found that CFL1 silencing induced G1 phase arrest as determined by flow cytometry, promoted apoptosis as determined by cell apoptosis assay and reduced the formation of lamellipodia, decreased cell migration by wound healing assay, and inhibited the ability of cell invasion as determined by Transwell assay, which indicated that CFL1 silencing may suppress the aggressive phenotype of VSCC cells. Consistently, Polachini et al found that knockdown of CFL1 expression by siRNA significantly inhibited the invasive ability of oral cancer cells in vitro as determined as determined by Boyden chamber assay (13). In addition, a previous study reported that silencing of CFL1 by shRNA delayed tumor metastasis in mice with lung cancer (14). Additionally, we found that the knockdown of 

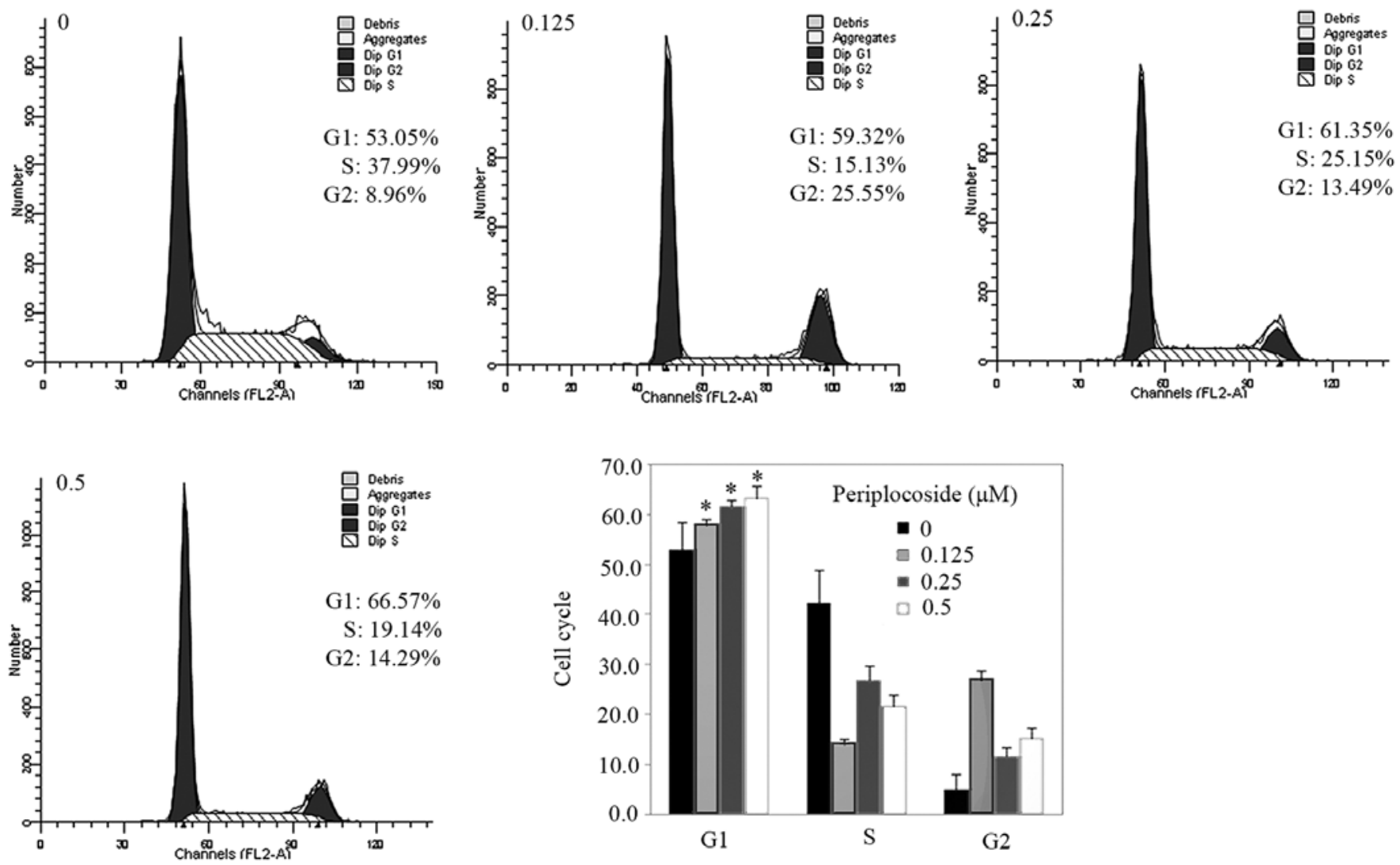

Figure 11. Effects of periplocoside on vulvar carcinoma cell cycle. Periplocoside exposure induced G1 arrest in the SW962 cells compared with that in the normal cells. Data are expressed as the mean \pm standard deviation, ${ }^{*} \mathrm{P}<0.05$.
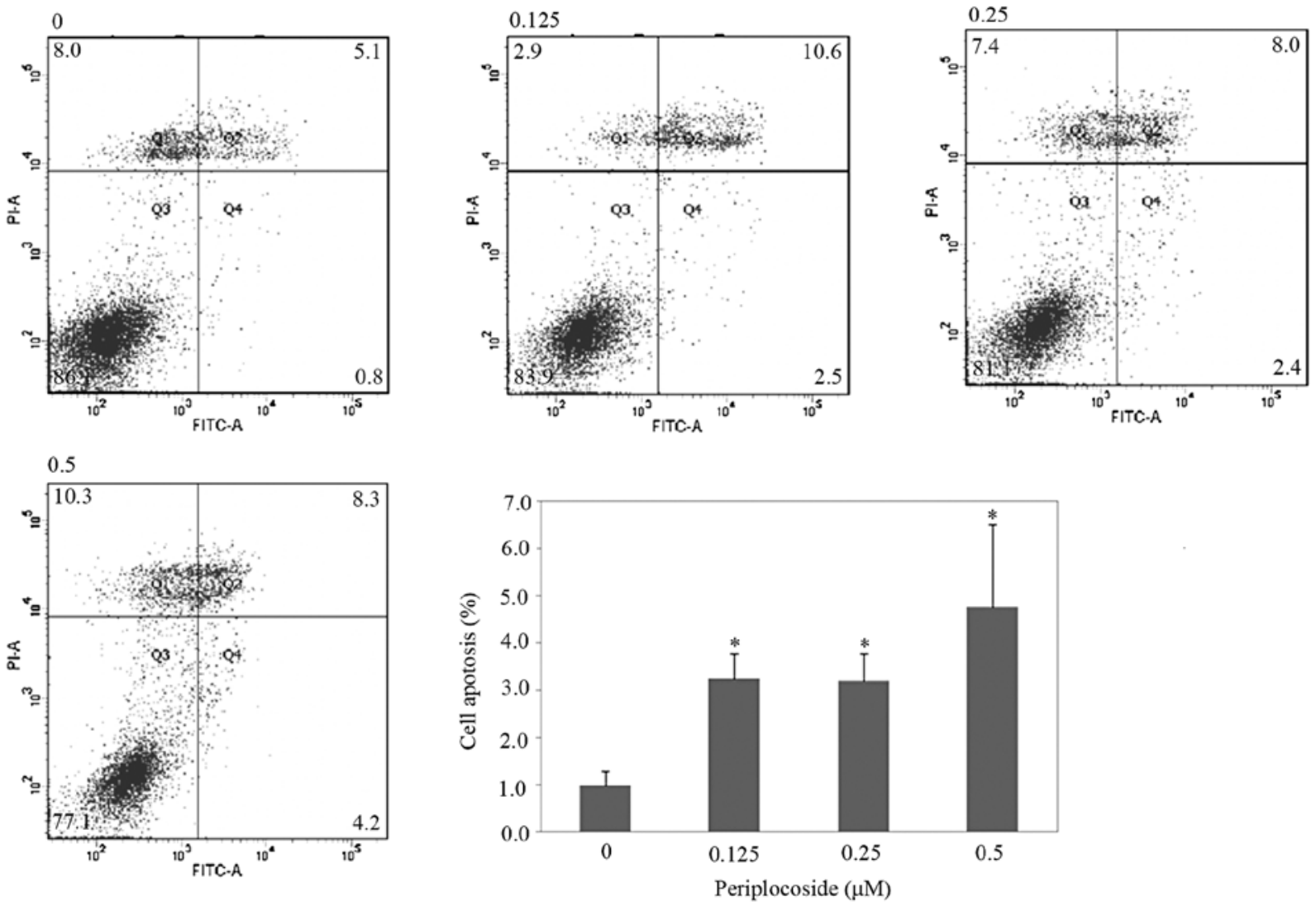

Figure 12. Effects of periplocoside on vulvar carcinoma cell apoptosis. Periplocoside exposure significantly induced apoptosis in the SW962 cells compared with that in the normal cells. Data are expressed as the mean \pm standard deviation, ${ }^{*} \mathrm{P}<0.05$. 

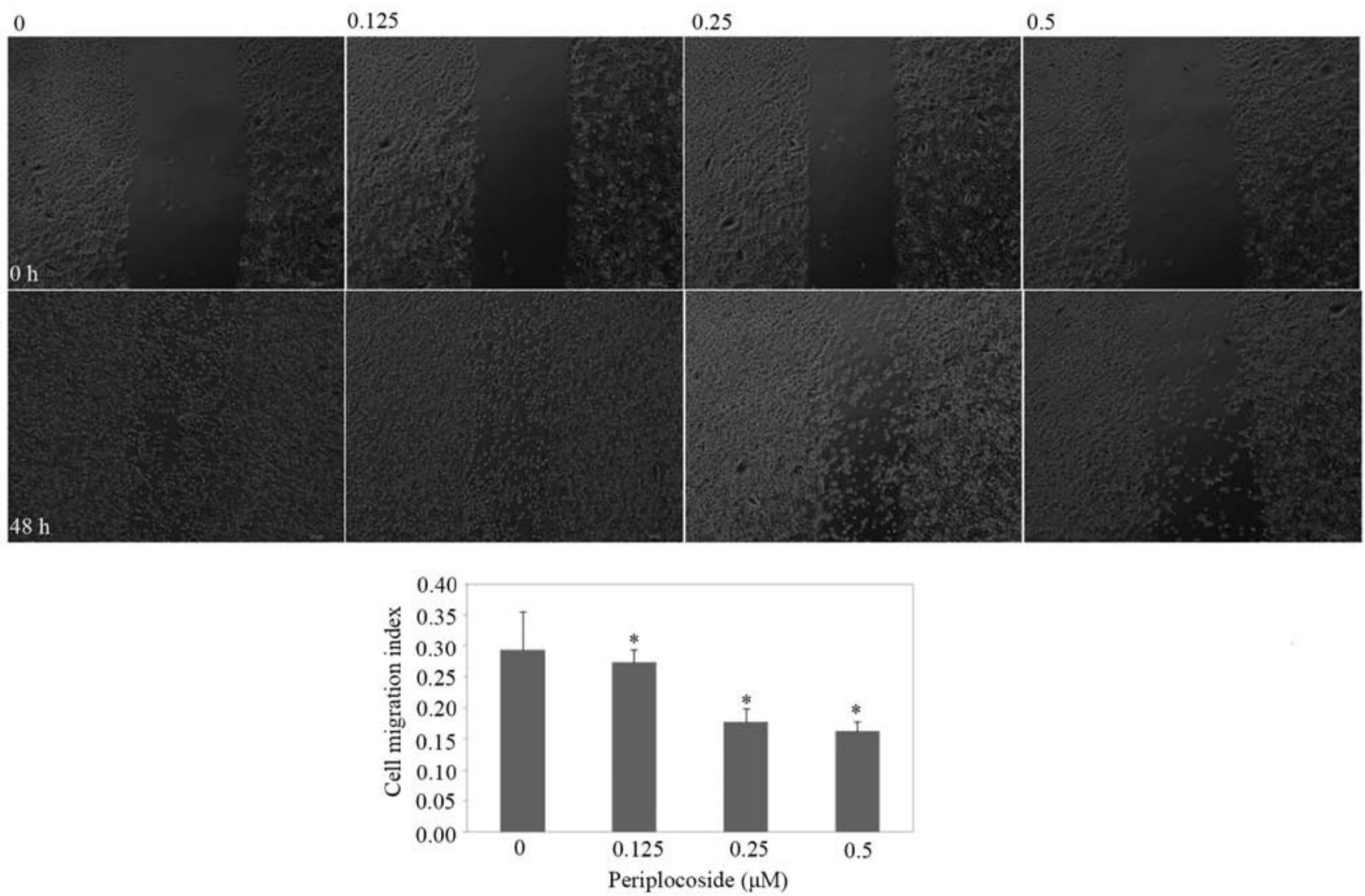

Figure 13. Effects of periplocoside on vulvar carcinoma cell migration. Periplocoside exposure significantly reduced cell migration ability of the SW962 cells compared with that of the normal cells. Data are expressed as the mean \pm standard deviation, ${ }^{*} \mathrm{P}<0.05$.
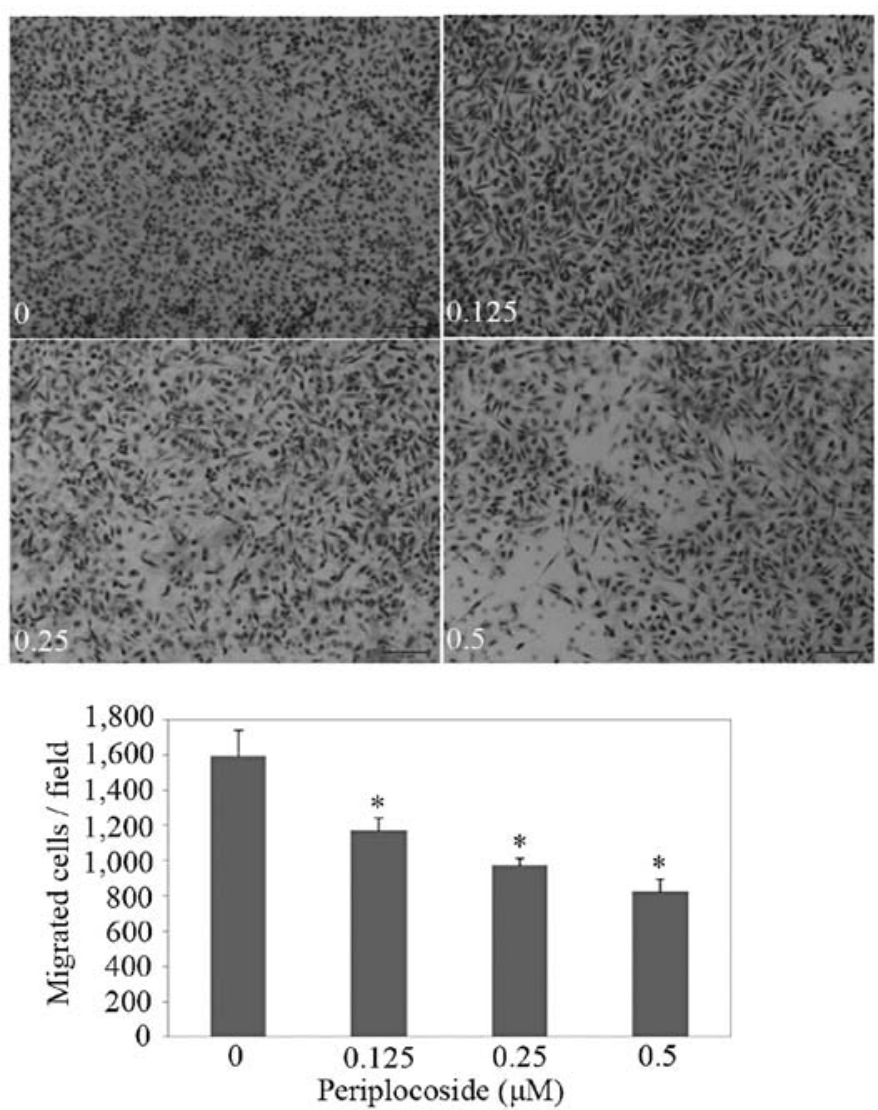

Figure 14. Effects of periplocoside on vulvar carcinoma cell invasion. Periplocoside exposure significantly reduced cell invasion ability in the SW962 cells compared with that in the normal cells. Data are expressed as the mean \pm standard deviation, ${ }^{*} \mathrm{P}<0.05$. 


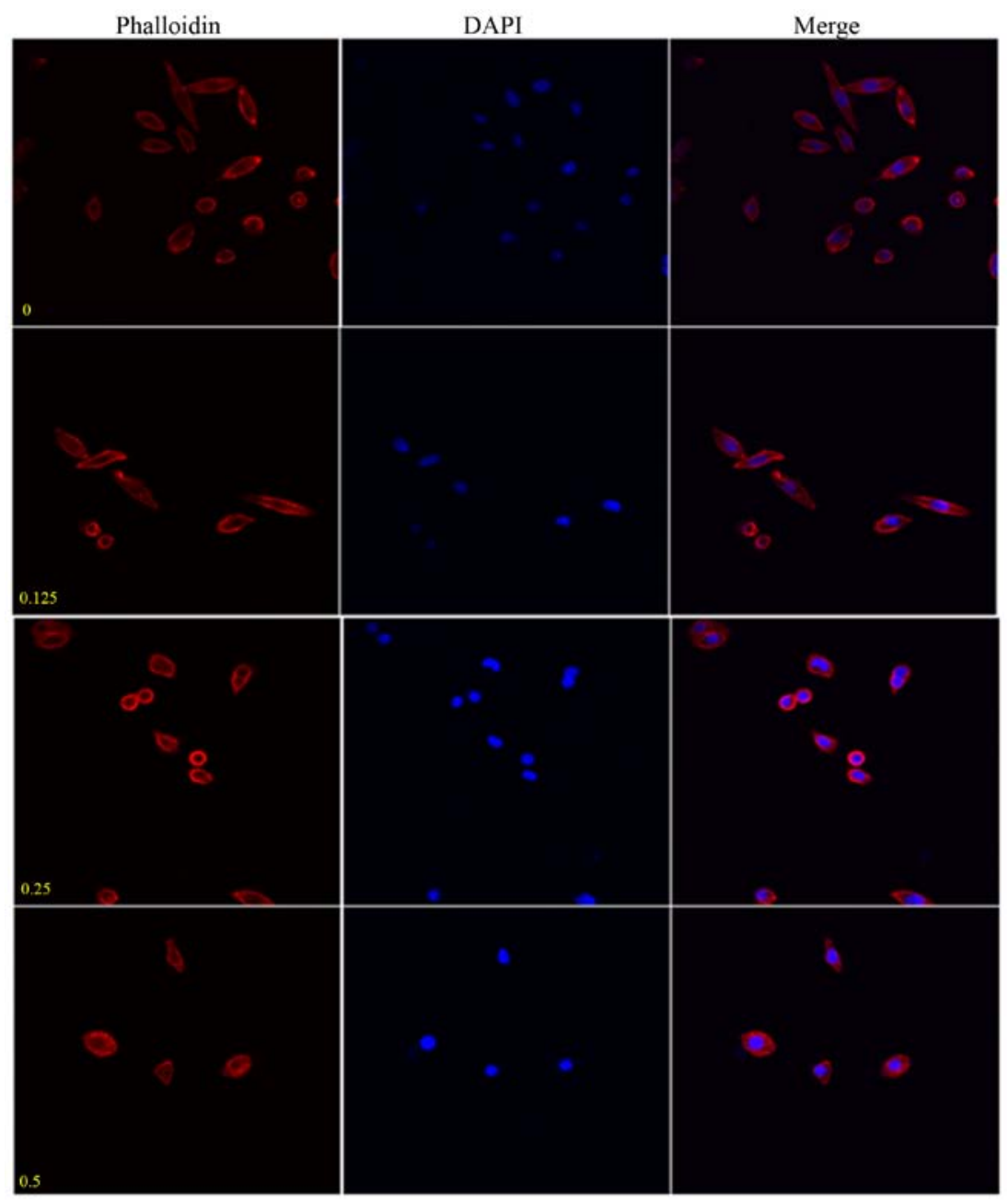

Figure 15. Periplocoside exposure suppresses vulvar carcinoma cell lamellipodium formation. Periplocoside exposure suppressed vulvar carcinoma cell lamellipodium formation in the SW962 cells.

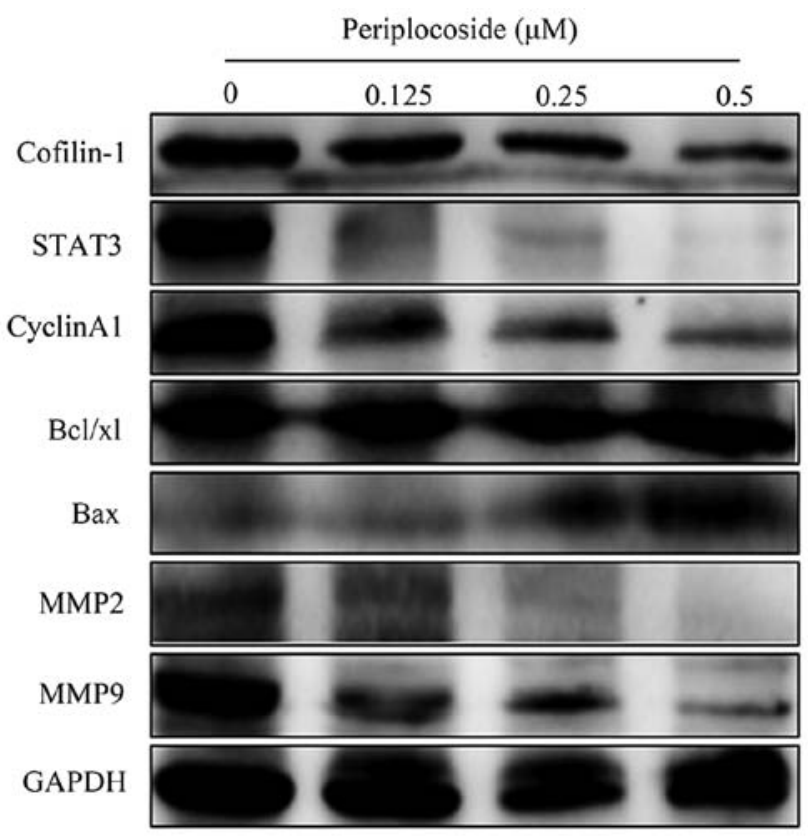

Figure 16. Effects of periplocoside exposure on vulvar carcinoma cell genotype. Periplocoside exposure downregulated CFL1, MMP2, MMP9, cyclin A1, STAT3 and Bcl-xL protein expression while upregulating Bax protein expression in the SW962 cells.
CFL1 significantly downregulated Bcl-xL expression and upregulated Bax expression, indicating that CFL1 knockdown promotes cell apoptosis by mediating apoptosis-related proteins. CFL1 knockdown also suppressed the expression of cyclin A1 that accelerates the transition of the G1/S phase (15), suggesting that CFL1 knockdown inhibits the progression of tumor cells by inducing G1 arrest. CFL1 silencing reduced the protein expression of MMP2 and MMP9, which implies that CFL1 silencing inhibits tumor invasion and metastasis by suppressing the degradation of the extracellular matrix. Furthermore, we observed that the silencing of CFL1 inhibited STAT3 expression. STAT3 is a critical member of the signal transducer and activator of transcription family, and is activated by a wide variety of cytokines and growth factors. STAT3 inhibition or ablation has been shown repeatedly to reduce the growth of tumors, induce apoptosis, and attenuate tumor cell invasion and metastasis $(16,17)$, which indicates that the antitumor effects of CFL1 silencing are achieved by inhibiting the STAT3 pathway.

Periplocoside (18), a traditional Chinese medicine, is derived from Cortex periplocae and plays an important role in clinical treatment, including anti-inflammation, enhancing bones and muscles, and nervous system stimulation. Recently, some researchers have demonstrated that periplocoside 
exhibits strong inhibitory effects on the proliferation of many tumor cell lines in vitro, such as SW480, SMC-7721, TE13, BGC-823, MCF-7 and PC3 $(19,20)$. Herein, we observed that periplocoside downregulated CFL1 expression in SW962 cells and inhibited cell growth in a dose-dependent manner, which could be attributed to the inhibition of proliferation, the induction of apoptosis, reduced migration and low invasive ability. Meanwhile, we found that the protein expression levels of MMP2, MMP9, cyclin A1, Bcl-xL and STAT3 were reduced, while Bax expression was increased after treatment with periplocoside, which suggests that periplocoside may inhibit the expression of these proteins via the suppression of CFL1.

In conclusion, we demonstrated that abnormal CFL1 expression may affect vulvar carcinogenesis and subsequent progression. CFL1 silencing by CFL1 siRNA significantly inhibited VSCC cell progression, which suggests that CFL1 may be used as a potential therapeutic target for vulvar cancer. In addition, periplocoside, which was utilized in the present study for the clinical treatment of vulvar cancer, showed strong antitumor effects by suppressing CFL1 expression.

\section{Acknowledgements}

The present study was supported by the Natural Scientific Foundation of China (no. 30973190).

\section{References}

1. Siegel R, Naishadham D and Jemal A: Cancer statistics, 2013. CA Cancer J Clin 63: 11-30, 2013.

2. Sideri M, Jones RW, Wilkinson EJ, Preti M, Heller DS, Scurry J, Haefner $\mathrm{H}$ and Neill S: Squamous vulvar intraepithelial neoplasia: 2004 modified terminology, ISSVD Vulvar Oncology Subcommittee. J Reprod Med 50: 807-810, 2005.

3. Buttmann-Schweiger N, Klug SJ, Luyten A, Holleczek B, Heitz F, du Bois A and Kraywinkel K: Incidence patterns and temporal trends of invasive nonmelanotic vulvar tumors in Germany 1999-2011. A population-based cancer registry analysis. PLoS One 10: e0128073, 2015.

4. Akhtar-Danesh N, Elit L and Lytwyn A: Trends in incidence and survival of women with invasive vulvar cancer in the United States and Canada: A population-based study. Gynecol Oncol 134: 314-318, 2014

5. Marsden DE and Hacker NF: Contemporary management of primary carcinoma of the vulva. Surg Clin North Am 81: 799-813, 2001

6. Wang WS, Zhong HJ, Xiao DW, Huang X, Liao LD, Xie ZF, $\mathrm{Xu}$ XE, Shen ZY, Xu LY and Li EM: The expression of CFL1 and N-WASP in esophageal squamous cell carcinoma and its correlation with clinicopathological features. Dis Esophagus 23 : $512-521,2010$.
7. Wang W, Mouneimne G, Sidani M, Wyckoff J, Chen X, Makris A, Goswami S, Bresnick AR and Condeelis JS: The activity status of cofilin is directly related to invasion, intravasation, and metastasis of mammary tumors. J Cell Biol 173: 395-404, 2006.

8. Wang W, Eddy R and Condeelis J: The cofilin pathway in breast cancer invasion and metastasis. Nat Rev Cancer 7: 429-440, 2007.

9. Hotulainen P, Paunola E, Vartiainen MK and Lappalainen P: Actin-depolymerizing factor and cofilin-1 play overlapping roles in promoting rapid $\mathrm{F}$-actin depolymerization in mammalian nonmuscle cells. Mol Biol Cell 16: 649-664, 2005.

10. van Rheenen J, Song X, van Roosmalen W, Cammer M, Chen X, Desmarais V, Yip SC, Backer JM, Eddy RJ and Condeelis JS: EGF-induced $\mathrm{PIP}_{2}$ hydrolysis releases and activates cofilin locally in carcinoma cells. J Cell Biol 179: 1247-1259, 2007.

11. Lu LI, Fu NI, Luo XU, Li XY and Li XP: Overexpression of cofilin 1 in prostate cancer and the corresponding clinical implications. Oncol Lett 9: 2757-2761, 2015.

12. Zhou J, Wang Y, Fei J and Zhang W: Expression of cofilin 1 is positively correlated with the differentiation of human epithelial ovarian cancer. Oncol Lett 4: 1187-1190, 2012.

13. Polachini GM, Sobral LM, Mercante AMC, Paes-Leme AF, XavierFC,Henrique T, Guimarães DM, Vidotto A,Fukuyama EE, Góis-Filho JF, et al: Proteomic approaches identify members of cofilin pathway involved in oral tumorigenesis. PLoS One 7: e50517, 2012.

14. Peng XC, Gong FM, Zhao YW, Zhou LX, Xie YW, Liao HL, Lin HJ, Li ZY, Tang MH and Tong AP: Comparative proteomic approach identifies PKM2 and cofilin-1 as potential diagnostic, prognostic and therapeutic targets for pulmonary adenocarcinoma. PLoS One 6: e27309, 2011.

15. Ji P, Agrawal S, Diederichs S, Bäumer N, Becker A, Cauvet T, Kowski S, Beger C, Welte K, Berdel WE, et al: Cyclin A1, the alternative A-type cyclin, contributes to G1/S cell cycle progression in somatic cells. Oncogene 24: 2739-2744, 2005.

16. Wake MS and Watson CJ: STAT3 the oncogene - still eluding therapy? FEBS J 282: 2600-2611, 2015.

17. Katoh D, Nishizuka M, Osada S and Imagawa M: Fad104, a positive regulator of adipocyte differentiation, suppresses invasion and metastasis of melanoma cells by inhibition of STAT3 activity. PLoS One 10: e0117197, 2015.

18. Du YY, Liu X and Shan BE: Periplocin extracted from cortex periplocae induces apoptosis of SW480 cells through inhibiting the Wnt/beta-catenin signaling pathway. Ai Zheng 28: 456-460, 2009 (In Chinese).

19. Zhao L, Shan B, Du Y, Wang M, Liu L and Ren FZ: Periplocin from Cortex periplocae inhibits cell growth and down-regulates survivin and c-myc expression in colon cancer in vitro and in vivo via $\beta$-catenin/TCF signaling. Oncol Rep 24: 375-383, 2010.

20. Lu Z, Song Q, Yang J, Zhao X, Zhang X, Yang P and Kang J: Comparative proteomic analysis of anti-cancer mechanism by periplocin treatment in lung cancer cells. Cell Physiol Biochem 33: 859-868, 2014. 